\title{
A brief background of Neurology in Mexico
}

\section{Breve historia de la neurología en México}

\author{
Alfredo Ramírez-González ${ }^{1}$ and Ildefonso Rodríguez-Leyva ${ }^{2}$ \\ ${ }^{1}$ Department of Genetics and Genomics, Instituto Nacional de Rehabilitación “Luis Guillermo Ibarra", Mexico City; ${ }^{2}$ Department of Neurology, Faculty \\ of Medicine, Hospital Central "Dr. Ignacio Morones Prieto", Universidad Autónoma de San Luis Potosí, San Luis Potosí, Mexico
}

There are several events that can make a difference in the evolution of a society, some important facts are presented in this chronological account of world events and the history of Mexican neurology:

1500 B.C.

Mayan evidence of trepanation for god sacrifices, for relieving migraine or traumatic head bleeding intervention.

1500 B.C.

Edwin-Smith and Ebber's Papyrus: First treatise on herbal medicine and migraine treatments.

\section{B.C.}

The Corpus Hippocraticum states that Epilepsy is not a "sacred disease" but rather a cerebral alteration of its equilibrium.

\section{DC.}

"Tlazoltéotl", goddess of Medicine. Polytheism and magical beliefs mixed with observations and herbal medicine.

1500 DC.

The oldest American culture trepanation was performed, for example, for severe migraine, "to release demons" causing epilepsy, or to drain epidural or subdural hematomas. Mescaline was used as psychotropic and anesthetic.

\section{DC.}

The oldest American culture trepanation was performed, for example, for severe migraine, "to release demons" causing epilepsy, to drain epidural or subdural hematomas. Mescaline as psychotropic and anesthetic.

1400 DC.

Epilepsy as a 'divine disease', distinction between GTC ("Huapahualiztti") and myoclonic crisis ("Hixcayotl”).

1300 DC.

"The Great Tenochtitlan" (by Diego Rivera: 1945); "Tlazoltéotl," goddess of Medicine.

Polytheism and magical beliefs mixed with observations and herbal medicine.

1551 DC.

The Royal and Pontifical University of Mexico (now Universidad Nacional Autónoma de México [UNAM]) is founded. A few years later, on 1578, the first chair of/ in medicine in Latin America was established.

1579-1592 DC.

"A Brief Treaty of Anatomy and Surgery", written by Agustín Farfán describing trepanation procedure, its indications and technique.

Rising of Psychiatry in Mexico and America: Friar Bernardino de Alvarez became pioneer with the foundation on of San Hipolito's, Holy Cross, the first psychiatric facilities in the continent and Pontifical University of Mexico, Manuel Carpio started the general and nervous physiology chair while Casimiro Liceaga became in charge of the first chair in mental illnesses in the continent.

\section{Correspondence:}

Ildefonso Rodríguez-Leyva

E-mail: ilrole@yahoo.com.mx
Available online: 21-10-2020

Rev Mex Neuroci. 2020;21(5):178-179 www.revmexneurociencia.com 1665-5044/ @ 2020 Academia Mexicana de Neurología A.C. Published by Permanyer. This is an open access article under the CC BY-NC-ND license (http://creativecommons.org/licenses/by-nc-nd/4.0/). 


\section{7-1873-1906}

Purkinje, Golgi, and Cajal achieved with a novel silver stain to describe the "Neuronal Doctrine" and the synapse, with the latter 2 being awarded with the Nobel Prize in Medicine or Physiology.

Charcot instituted the first chair of Neurology at La Pitié Salpêtrière. Mexican neurologists started to then follow the French school through the Brevie Neurologie journal and to train in Paris.

\section{2}

Miguel Alvarado, first Neurology Chairman at the Royal and Pontifical University of Mexico, which included professors of pathology, surgery and morphological description of the nervous system.

\section{1}

Rafael Lavista describes a case of apparent Bravais-Jacksonian epilepsy and its notorious improvement posterior to the surgery, as well as the successful cerebral tumor resection and recovery of a young boy.

\section{9-1910}

The first public and private mental institutions started attending patients with the novel advances in psychiatry. The most important mental infirmaries were the Rafael Lavista's and La Castañeda, this last one founded upon the direct instruction of Porfirio Diaz.

\section{5}

Boom in nervous physiology thanks to Harvard researchers Walter Cannon and his Mexican collaborators Arturo Roseblueth and José Joaquin Izquierdo, who described the function of the autonomic nervous system.

1924-1936

EEG invention by Hans Berger and alpha-waves description; posteriorly, Teodoro Flores Covarrubias built his own and started electrophysiological cabinets in the main hospitals in the country.

\section{5-1940}

Established in 1937, the Mexican Society of Neurology and Psychiatry allowed the national integration of an important spectrum of specialists in the field of neurosciences.

The National Institute of Neurology and Neurosurgery opens its doors with the first stereotactic-guided surgery in our country performed by its founder, Manuel Velasco Suarez.

\section{1-1975}

The certified Board for the Mexican Council of Neurology was established and the Mexican Academy of Neurology, and the National Chapter of the International League Against Epilepsy "CAMELICE" were founded.

\section{0}

New neurological societies in critical areas have appeared: AMEVASC (for cerebrovascular disease), Mexctrims (multiple sclerosis and immunological problems), AMCEMIG (for the study of headache and migraine), and SOMA (abnormal movements), among others.

Ten neurology programs for the formation of new specialists are open in the whole country, looking for international recognition (WFN, ANA) upon the direct instruction of and the Board of the Mexican Neurology Council.

There are so many things to do in our beloved Mexico in order to improve the education in the neurological area but our societies and institutions are working hard for making it possible. The quest is to have the best quality and best educated neurologists in Mexico, following the standards of the best in the world. 